\title{
Diazoxide affects mitochondrial bioenergetics by the opening of mKATP channel on submicromolar scale
}

\author{
Olga Akopova ${ }^{\text {* }}$, Liudmila Kolchinskaya' ${ }^{1}$, Valentina Nosar², Iryna Mankovska² and Vadim Sagach ${ }^{1}$
}

\begin{abstract}
Background: Cytoprotection afforded by mitochondrial ATP-sensitive $\mathrm{K}^{+}$-channel (mK $\mathrm{ATP}_{\text {-channel) opener diazoxide }}$ (DZ) largely depends on the activation of potassium cycle with eventual modulation of mitochondrial functions and ROS production. However, generally these effects were studied in the presence of Mg.ATP known to block K ${ }^{+}$ transport. Thus, the purpose of our work was the estimation of DZ effects on $\mathrm{K}^{+}$transport, $\mathrm{K}^{+}$cycle and ROS production in rat liver mitochondria in the absence of Mg.ATP.

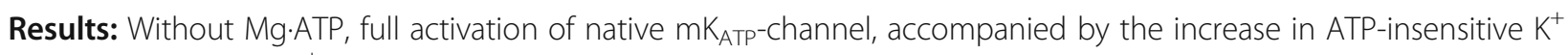
uptake, activation of $\mathrm{K}^{+}$-cycle and respiratory uncoupling, was reached at $\leq 0.5 \mu \mathrm{M}$ of $\mathrm{DZ}$. Higher diazoxide

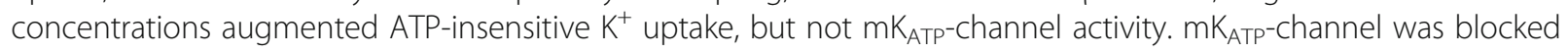

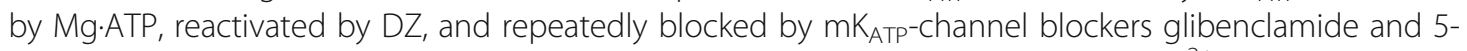
hydroxydecanoate, whereas ATP-insensitive potassium transport was blocked by $\mathrm{Mg}^{2+}$ and was not restored by DZ. High sensitivity of potassium transport to DZ in native mitochondria resulted in suppression of mitochondrial ROS production caused by the activation of $\mathrm{K}^{+}$-cycle on sub-micromolar scale. Based on the oxygen consumption study, the share of $\mathrm{mK}_{\mathrm{ATP}}$-channel in respiratory uncoupling by DZ was found.

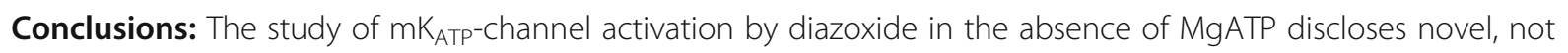

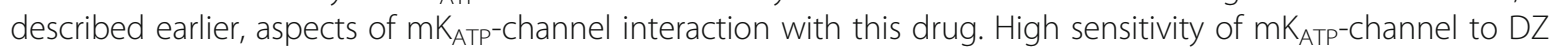
results in the modulation of mitochondrial functions and ROS production by DZ on sub-micromolar concentration scale. Our experiments led us to the hypothesis that under the conditions marked by ATP deficiency affinity of $\mathrm{mK}_{\text {ATP }}$-channel to DZ can increase, which might contribute to the high effectiveness of this drug in cardio- and neuroprotection.
\end{abstract}

Keywords: Diazoxide, Potassium transport, $\mathrm{mK}_{\text {ATP }}$-channel, Potassium cycle, Mild uncoupling, ROS production

\section{Background}

Cytoprotective effects afforded by the mitochondrial $\mathrm{K}_{\mathrm{ATP}}$-channel ( $\mathrm{mK}_{\mathrm{ATP}}$-channel) opening generally are supposed to result from the modulation of mitochondrial functions and protective redox signaling triggered by ATP-sensitive $\mathrm{K}^{+}$transport, which helped tissues

\footnotetext{
*Correspondence: olga.akopova01@mail.ru; olga-akopova@biph.kiev.ua ${ }^{1}$ Circulation department, Bogomoletz Institute of Physiology, NAS of Ukraine, Bogomoletz str. 4, Kiev 01601, Ukraine

Full list of author information is available at the end of the article
}

recovery from the impairments caused by ischemic, hypoxic [1-5] and metabolic stress conditions [6-9]. Numerous pathophysiological conditions primarily affect mitochondrial bioenergetic. Prevention of $\mathrm{Ca}^{2+}$ overload [8], restoration of ATP synthesis, prevention of mitochondrial depolarization [3] and the regulation of mitochondrial ROS production resulting from $\mathrm{mK}_{\mathrm{ATP}}$-channels opening in different cell types were shown to block apoptotic and necrotic pathways triggered by multiple pathophysiological states [1-9]. 
The disclosure of the mechanisms underlying the modulation of mitochondrial functions by $\mathrm{mK}_{\mathrm{ATP}}$-channels openers (pinacidil, diazoxide, nicorandil) needs the study of the direct effects of these drugs on ATPsensitive potassium transport in mitochondria and their consequences for mitochondrial functions. However, their appraisal at present is complicated because of several off-target effects of pharmacological $\mathrm{mK}_{\mathrm{ATP}}$-channel openers $[10,11]$.

Of the known $\mathrm{mK}_{\mathrm{ATP}}$-channel openers diazoxide is most widely used one. Apparent activation constants for diazoxide show its much greater affinity to mitochondrial than plasma membrane, $K_{\mathrm{ATP}}$-channel [12]. Consistent with the present views, bioenergetic effects of diazoxide and its impact on ROS production are based on "mild uncoupling" of the respiratory chain due to the opening of $\mathrm{mK}_{\mathrm{ATP}}$-channel and the activation of mitochondrial potassium cycle $[13,14]$. But similar to other drugs, many side effects of diazoxide were described, not caused directly by $\mathrm{mK}_{\mathrm{ATP}}$-channel opening and capable of affecting ROS production in a similar way, such as protonophoric properties at high micromolar concentrations [15], suppression of SDH (Complex II) activity and respiratory inhibition [16]. Thus proper appraisal of bioenergetic effects of $\mathrm{mK}_{\mathrm{ATP}}$-channel opening using diazoxide as pharmacological tool requires the study of the direct effects of this drug on potassium transport in mitochondria.

A common methodical approach to the activation of $\mathrm{mK}_{\mathrm{ATP}}$-channel by $\mathrm{mK}_{\mathrm{ATP}}$-channel openers is based on preliminary blockage of the channel by Mg.ATP and consequent activation, which for diazoxide lies in micromolar concentration area $(\sim 30 \mu \mathrm{M})$. Thus, functional effects of diazoxide as $\mathrm{mK}_{\mathrm{ATP}}$-channel opener generally were assessed in the presence of Mg.ATP [13, 17]. The main limitation of this approach is that it interferes with the study of the effects of $\mathrm{mK}_{\mathrm{ATP}}$-channel opening on potassium cycle because of the blockage of $\mathrm{K}^{+} / \mathrm{H}^{+}$-exchanger by $\mathrm{Mg}^{2+}$ ions [13]. For this reason, proper understanding of bioenergetic effects of diazoxide as well as diazoxide properties as $\mathrm{mK}_{\mathrm{ATP}}$-channel opener, require the estimation of direct effects of diazoxide on potassium transport and mitochondrial functions in native mitochondria, in the absence of Mg.ATP. The aim of this work was to revise the effects of diazoxide on $\mathrm{mK}_{\mathrm{ATP}}$-channel activity, potassium transport, potassium cycle and ROS production in native rat liver mitochondria, in the absence of Mg.ATP.

\section{Results}

The effect of diazoxide on state 4 oxygen consumption in rat liver mitochondria

Potassium transport is known to be coupled to the rate of state 4 respiration, so to test the effect of diazoxide on mitochondrial $\mathrm{K}^{+}$transport, the effect of this drug on the respiration was studied. Based on polarographic records, in the absence of Mg.ATP, diazoxide produced about twofold increase in the rate of glutamate-driven respiration $\left(J_{\mathrm{O} 2}\right)$ in native mitochondria, from $12.0 \pm 1.0$ to $26.0 \pm 0.9$ ng-at. O. $\mathrm{min}^{-1} \cdot \mathrm{mg}^{-1}$ (Fig. 1a, black circles; Fig. 1 Suppl). The effect was not dependent on simultaneous or sequential additions of the respiratory substrate and diazoxide (Fig. 1b, Suppl). Also, as we observed earlier [18], no apparent depolarization of mitochondria by diazoxide was observed within the timeframes of the respiration assays. The effect of diazoxide on mitochondrial respiration was concentration dependent, specific for $\mathrm{K}^{+}$-based medium, and was not observed when $\mathrm{K}^{+}$was isotonically replaced by $\mathrm{Na}^{+}$(Fig. 1a, empty circles). In the absence of Mg.ATP the activation of state 4 respiration occurred at submicromolar concentrations of the drug, $\leq 0.5 \mu \mathrm{M}$, whereas Mg.ATP led to the shift of the activation curve to micromolar concentrations (Fig. 1b). Without Mg.ATP, at concentrations above $\sim 0.5 \mu \mathrm{M}$, up to high micromolar level $(\sim 100 \mu \mathrm{M})$ no further stimulation of respiration by diazoxide was found (Fig. 1a, b).

To ascertain the effect of diazoxide on native $\mathrm{mK}_{\mathrm{ATP}^{-}}$ channel activity, we determined its share in state 4 respiration from the respiration rate differences sensitive to the addition of $\mathrm{Mg}^{2+}$ and ATP (Fig. 1c, d, Suppl,) in the absence and the presence of $0.5 \mu \mathrm{M}$ of diazoxide, which caused full stimulation effect of this drug on the respiration. Difference in the respiration rates sensitive to sequential additions of $\mathrm{Mg}^{2+}$ and ATP in $\mathrm{K}^{+}$-based medium without diazoxide have shown that the share of native $\mathrm{mK}_{\mathrm{ATP}}$-channel in the respiration was $4.0 \pm 1.0$ ng-at. O. $\mathrm{min}^{-1} \cdot \mathrm{mg}^{-1}$ (Fig. 1c) and this constituted about $30 \%$ of the total respiration rate. Under maximal respiration stimulation by diazoxide Mg.ATP-sensitive component of oxygen consumption rose to $7.9 \pm 1.1 \mathrm{ng}$-at. $\mathrm{O} \cdot \mathrm{min}^{-1} \cdot \mathrm{mg}^{-1}$ (Fig. 1c), which indicated twofold increase in ATP-sensitive $\mathrm{K}^{+}$uptake. In $\mathrm{Na}^{+}$-based medium $\mathrm{Mg}^{2+}$ similarly suppressed respiration, consistent with the notion of the ability of $\mathrm{Mg}^{2+}$ ions to block $\mathrm{Na}^{+}$uptake in mitochondria. However, in $\mathrm{Na}^{+}$-based medium none effects of diazoxide on $\mathrm{Mg}^{2+}$-sensitive and ATP-sensitive components of oxygen consumption were found (Fig. 1c), which proved specific modulation of MgATP-sensitive part of respiration related to $\mathrm{mK}_{\mathrm{ATP}}$-channel activity.

In the presence of Mg.ATP diazoxide failed to stimulate respiration in submicromolar concentration area (Fig. 1b, d), but full stimulation reached with micromolar concentrations of the drug [12] gave the same estimate of maximal $\mathrm{mK}_{\mathrm{ATP}}$-channel activity (Fig. 1d). This was confirmed by the blockage of the channel activated by diazoxide in the presence of MgATP by its blockers, glibenclamide and 5-HD, which in the absence of diazoxide under the same conditions had no effect on respiration, but abolished the stimulation of the respiration reached with $30 \mu \mathrm{M}$ diazoxide (Fig. 1d). Based on $\mathrm{K} / \mathrm{O}$ 

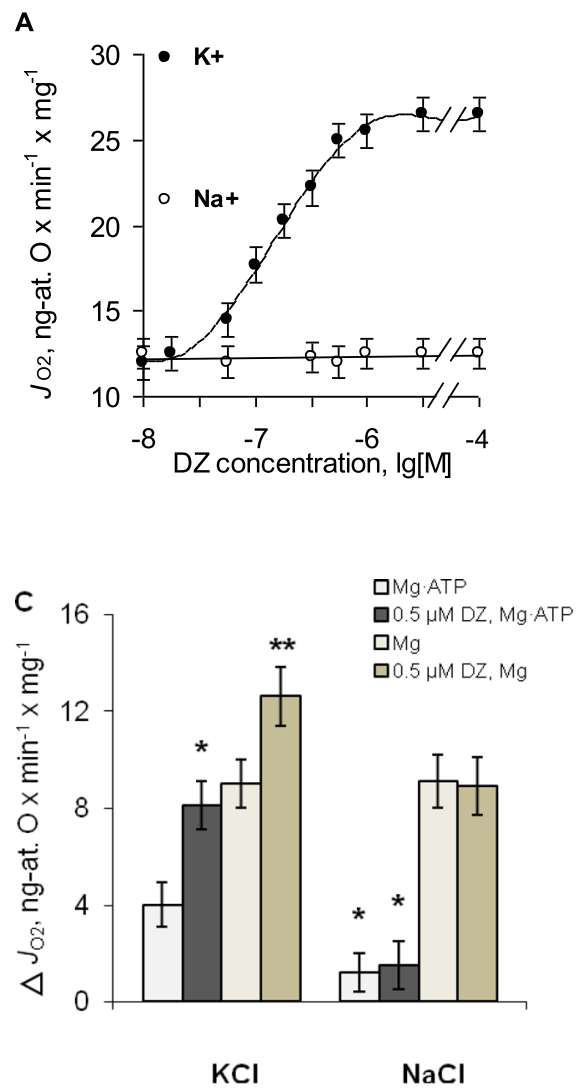
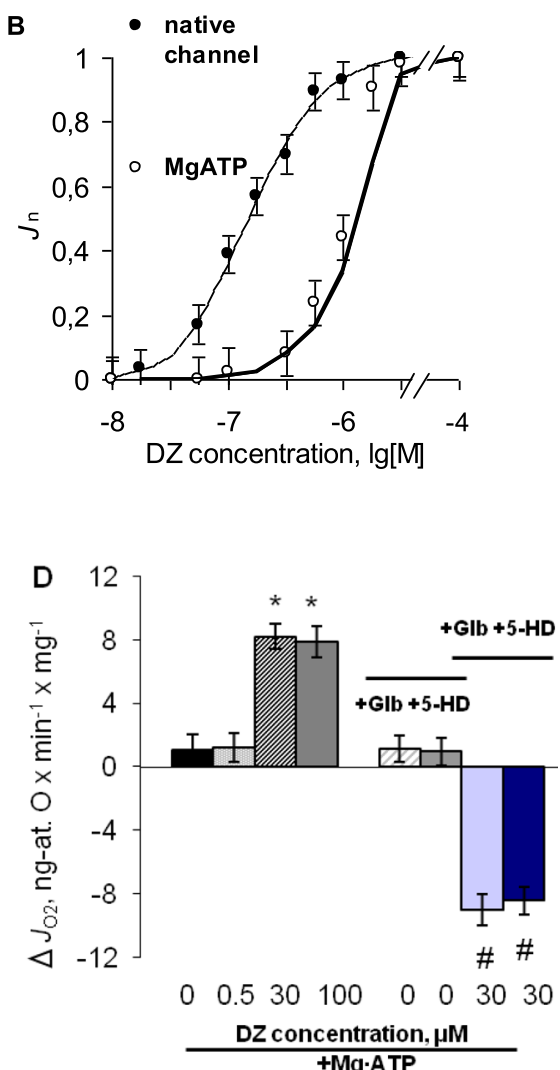

Fig. 1 The effect of diazoxide (DZ) on state 4 respiration in rat liver mitochondria in the absence and the presence of MgATP. a - Respiration rates in $\mathrm{K}^{+}$- and $\mathrm{Na}^{+}$-based media against DZ concentration, lg [M]; $\mathbf{b}$ - normalized respiration rates in the absence (native mitochondria) and the presence of Mg.ATP; $\mathbf{c}$ - respiration rate differences in $\mathrm{K}^{+}$- and $\mathrm{Na}^{+}$-based media sensitive to the addition of Mg.ATP and $\mathrm{Mg}{ }^{2+}$ in the absence and the presence of $0.5 \mu \mathrm{M} \mathrm{DZ;} \mathbf{d}$ - respiration rate differences in the presence of Mg.ATP sensitive to the addition of DZ, glibenclamide and 5HD. Additions are shown in the legends. $M \pm m, n=9 . \mathbf{c}, \mathbf{d}$ : ${ }^{*}-P<0.05$ vs. MgATP, 0 DZ; ${ }^{* *}-P<0.01$ vs. Mg ${ }^{2+} ; \#-P<0.01$ vs. MgATP, $30 \mu M$ DZ

stoichiometry of 10:1 for NADH-dependent substrates [19], the rate of ATP-sensitive potassium transport in rat liver mitochondria rose from $\sim 40$ to $\sim 80 \mathrm{nmol}$ $\mathrm{K}^{+} \cdot \mathrm{min}^{-1} \cdot \mathrm{mg}^{-1}$, which reflected maximal activity of the channel activated in the presence of MgATP. At high micromolar concentrations (up to $100 \mu \mathrm{M}$ ) diazoxide could not increase the share of $\mathrm{mK}_{\mathrm{ATP}}$-channel in oxygen consumption anymore (Fig. 1d).

In spite of more than twofold increase in the rate of state 4 respiration by diazoxide, it was rather surprising that contribution of $\mathrm{mK}_{\mathrm{ATP}}$-channel to oxygen consumption rested at the same level of $\sim 30-33 \%$, even at full respiration stimulation. As we observed, this was caused by simultaneous increment of ATP-insensitive component of respiration, found in standard $\mathrm{K}^{+}$-based medium from the difference in respiration rates sensitive to the addition of $\mathrm{Mg}^{2+}$ in the absence and the presence of diazoxide (Fig. 1c; Fig. 1c, d, Suppl). Since $\mathrm{Mg}^{2+}$ is known to block considerable part of $\mathrm{Na}^{+}$and $\mathrm{K}^{+}$transport, several types of $\mathrm{K}^{+}$channels and $\mathrm{K}^{+} /$ $\mathrm{H}^{+}$-exchange $[13,20]$, we supposed that the synchronized increase of both ATP-sensitive and ATP-insensitive constituents of state 4 respiration under the action of diazoxide (Fig. 1c) indicates the activation of ATP-insensitive potassium transport in parallel with $\mathrm{mK}_{\mathrm{ATP}}$-channel opening. Thus, to verify this assumption more directly, we studied the effect of diazoxide on potassium transport using light absorbance technique.

\section{The effect of diazoxide on mitochondrial matrix volume}

The effect of diazoxide on potassium transport, similar to oxygen consumption, was studied in the absence and the presence of $\mathrm{Mg} \cdot \mathrm{ATP}$. In standard incubation medium without diazoxide considerable matrix swelling indicated potassium uptake by energized mitochondria (Fig. 2a). As we observed from absorbance assay, in $\mathrm{K}^{+}$based medium mitochondrial swelling too was sensitive to submicromolar diazoxide concentrations $(\leq 0.5 \mu \mathrm{M})$. However, unlike the respiration, it was progressively increased with the rise of diazoxide concentration up to high micromolar level (Fig. 2a) which indicated increase in total potassium uptake. Maximal swelling observed in this work with $100 \mu \mathrm{M}$ DZ was a sort of a median between 

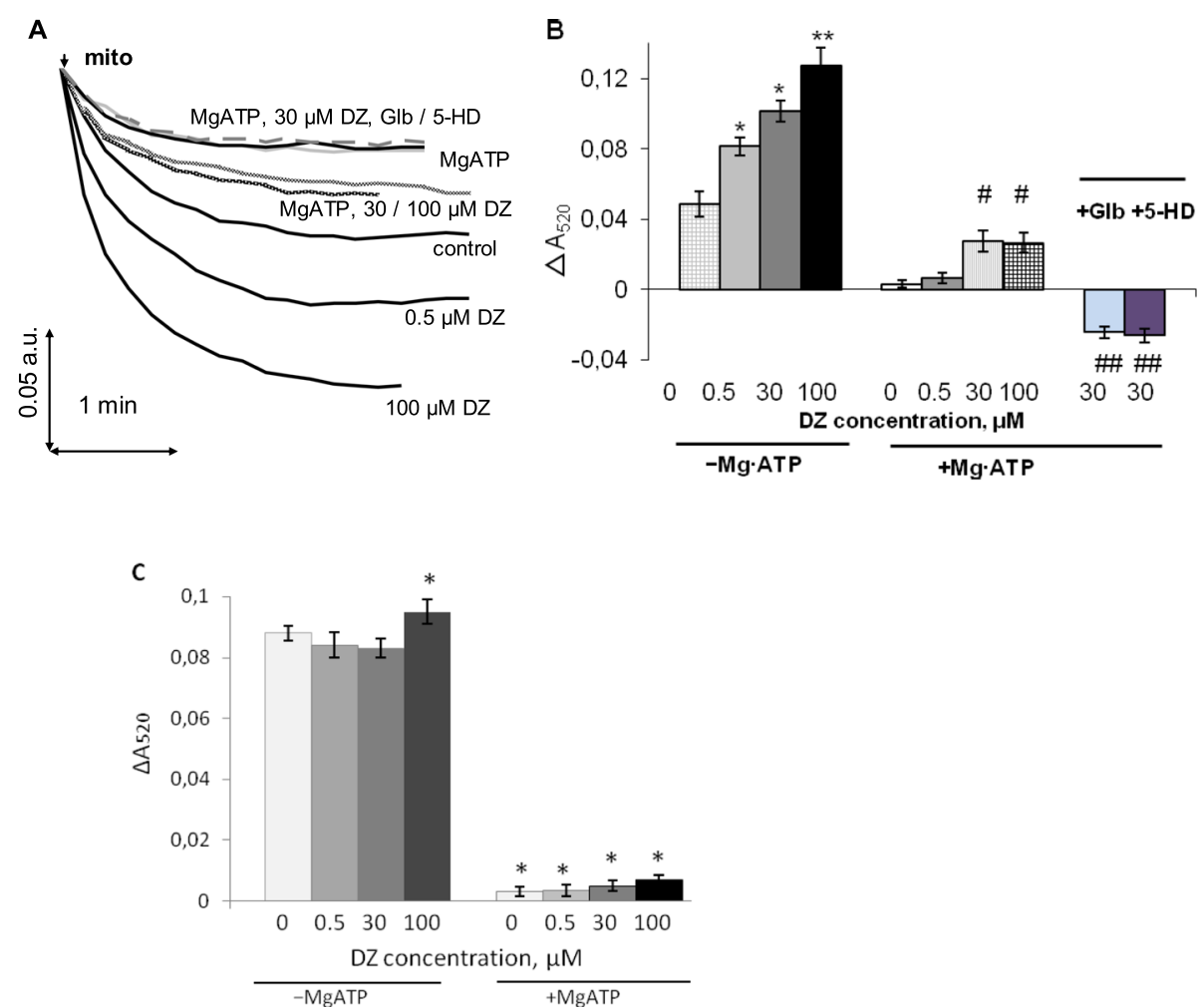

Fig. 2 Absorbance assay of the effect of $\mathrm{mK}_{\mathrm{ATP}}$-channel ligands on $\mathrm{K}^{+}$transport. a - typical pattern in standard incubation medium with DZ added at 0 , 0.5 and $100 \mu \mathrm{M}$ (as indicated); Mg.ATP (black line); Mg.ATP and DZ at 30 and $100 \mu \mathrm{M}$ (grey lines); Mg.ATP, $30 \mu \mathrm{M}$ DZ, glibenclamide (dotted line) or 5-HD (light grey); b, c - absorbance differences obtained in $\mathrm{K}^{+}-(\mathbf{b})$ and $\mathrm{Na}^{+}-(\mathbf{c})$ based media after the additions of DZ in the absence and the presence of Mg.ATP $(\mathbf{b}, \mathbf{c})$; after the additions of glibenclamide and 5-HD in the presence of Mg.ATP, $30 \mu \mathrm{M} \mathrm{DZ}(\mathbf{b})$. The values obtained in control in the presence of

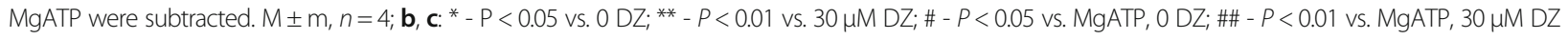

control and valinomycin (Fig. 2 Suppl). Thus to establish the share of $\mathrm{mK}_{\mathrm{ATP}}$-channel in potassium transport we selectively activated $\mathrm{mK}_{\mathrm{ATP}}$-channel by diazoxide in the $\mathrm{ab}$ sence and the presence of Mg.ATP (Fig. 2b).

After the addition of Mg.ATP to the medium, mitochondrial swelling was reduced to the minimum indicating essential block of potassium transport (Fig. 2a). Then, following Jaburek et al. [17], $\mathrm{mK}_{\mathrm{ATP}}$-channel was fully activated by $30 \mu \mathrm{M}$ of diazoxide (Fig. 2a). Difference in swelling amplitude sensitive to diazoxide stimulation in the presence of Mg.ATP reflected maximal $\mathrm{mK}_{\mathrm{ATP}}{ }^{-}$ channel activity and its share in $\mathrm{K}^{+}$transport (Fig. 2b). This was confirmed by the data showing the blockage of reactivated channel by glibenclamide and 5-HD (Figs. 2a, dotted lines; 2b). But while in the presence of Mg.ATP diazoxide failed to activate $\mathrm{mK}_{\mathrm{ATP}}$-channel anymore even at high micromolar concentrations (Figs. 2a and b), it exhibited potent activation of total potassium transport, starting from nanomolar concentrations without Mg.ATP (Fig. 2b). When $\mathrm{K}^{+}$was replaced by $\mathrm{Na}^{+}$, the activation of cation uptake was not observed either in the absence or the presence of MgATP, except weak stimulation found in the absence of MgATP at high diazoxide concentration, $100 \mu \mathrm{M}$ (Fig. 2c). Similarly to $\mathrm{K}^{+}$transport, $\mathrm{Mg}^{2+}$ blocked most part of the $\mathrm{Na}^{+}$uptake, which agreed with the above oxygen consumption assay, but blocking effect was not dependent on diazoxide (Figs. 1, 2c). So, in support of our previous observations, absorbance assays strongly indicated the activation of both ATP-sensitive (mK $\mathrm{mTP}_{\text {-channel) }}$ and ATP-insensitive potassium transport, highly susceptible to diazoxide activation in the absence of Mg.ATP. However, unlike oxygen consumption assay, this caused the decrease of the partial share of ATPsensitive potassium transport in total potassium uptake with the rise of diazoxide concentrations from nanomolar to high micromolar level (Fig. 2b). Thus, with the aim to ascertain the above observations independently, and quantify observed effects, we studied the effects of diazoxide on potassium transport using $\mathrm{pH}$-sensitive probe BCECF.

The effect of diazoxide on $\mathrm{mK}_{\mathrm{ATP}}$-channel activity, potassium transport and potassium cycle in rat liver mitochondria The effect of diazoxide on potassium uptake and $m K_{A T P^{-}}$ channel activity

The quantitative estimation of potassium transport was based on the notion that it is accompanied by the 
equivalent countertransport of protons, and simultaneous changes in matrix $\mathrm{pH}\left(\mathrm{pH}_{\mathrm{i}}\right)[13,21]$. Representative curves of the change in matrix $\mathrm{pH}\left(\Delta \mathrm{pH}_{\mathrm{i}}\right)$, starting from the addition of mitochondria to the medium, are shown on the Figs. 3a and Fig. 3a Suppl. The changes in matrix $\mathrm{pH}$ and the initial rates of potassium uptake $\left(V_{0}\right)$ in native mitochondria after the successive blockage of proton transport by $\mathrm{Mg}^{2+}$ and ATP in the absence and the presence of diazoxide (Fig. 3b, c), were found with the purpose to obtain the estimates of ATP-insensitive (sensitive to $\mathrm{Mg}^{2+}$ only) and ATP-sensitive (sensitive to Mg.ATP) constituents of $\mathrm{K}^{+}$transport (Fig. 3d, e). Also, the contribution of $\mathrm{mK}_{\mathrm{ATP}}$-channel to potassium transport and $\Delta \mathrm{pH}_{\mathrm{i}}$ was estimated from the activation of the channel by diazoxide in the presence of Mg.ATP (Fig. 3d, e).

As it was found from the experiments, at the concentration of $0.5 \mu \mathrm{M}$ shown to cause full activation of state 4 respiration in the absence of $\mathrm{Mg}^{2+}$ and ATP, diazoxide increased both matrix $\mathrm{pH}$ and $V_{0}$ of proton transport related to $\mathrm{K}^{+}$uptake (Fig. 3a, b, c and 2). In agreement with oxygen consumption data, $\mathrm{Mg}^{2+}$ ions blocked essential part of proton transport related to potassium uptake, which was suppressed further by Mg.ATP, in parallel reducing $\Delta \mathrm{pH}_{\mathrm{i}}$ (Fig. 3a, b, c, 4, 5). From sequential blockage of potassium transport by $\mathrm{Mg}^{2+}$ and ATP (Fig. 3b, c), it was found that in the absence of Mg.ATP native $\mathrm{mK}_{\mathrm{ATP}}$-channel activity contributed about $\sim 0.01$ units change in $\mathrm{pH}_{\mathrm{i}}$ and $\sim 40 \mathrm{nmol} \cdot \mathrm{min}^{-1} \cdot \mathrm{mg}^{-1}$ to $V_{0}$ of $\mathrm{K}^{+}$uptake (Fig. 3d, e). Diazoxide at submicromolar concentration $(0.5 \mu \mathrm{M})$ reliably increased $V_{0}$ of both ATPinsensitive and ATP-sensitive potassium uptake in native mitochondria, with related changes in $\mathrm{pH}_{\mathrm{i}}$ (Fig. 3d, e). Increase in $V_{0}$ of $\mathrm{Mg}$.ATP-sensitive potassium transport from $\sim 40$ to $60 \mathrm{nmol} \cdot \mathrm{min}^{-1} \cdot \mathrm{mg}^{-1}$ (Fig. 3e) indicated the activation of native $\mathrm{mK}_{\mathrm{ATP}}$-channel by sub-micromolar concentrations of this drug. Activity of native $\mathrm{mK}_{\mathrm{ATP}^{-}}$ channel stimulated by low diazoxide concentrations without Mg.ATP well agreed with the estimate of the
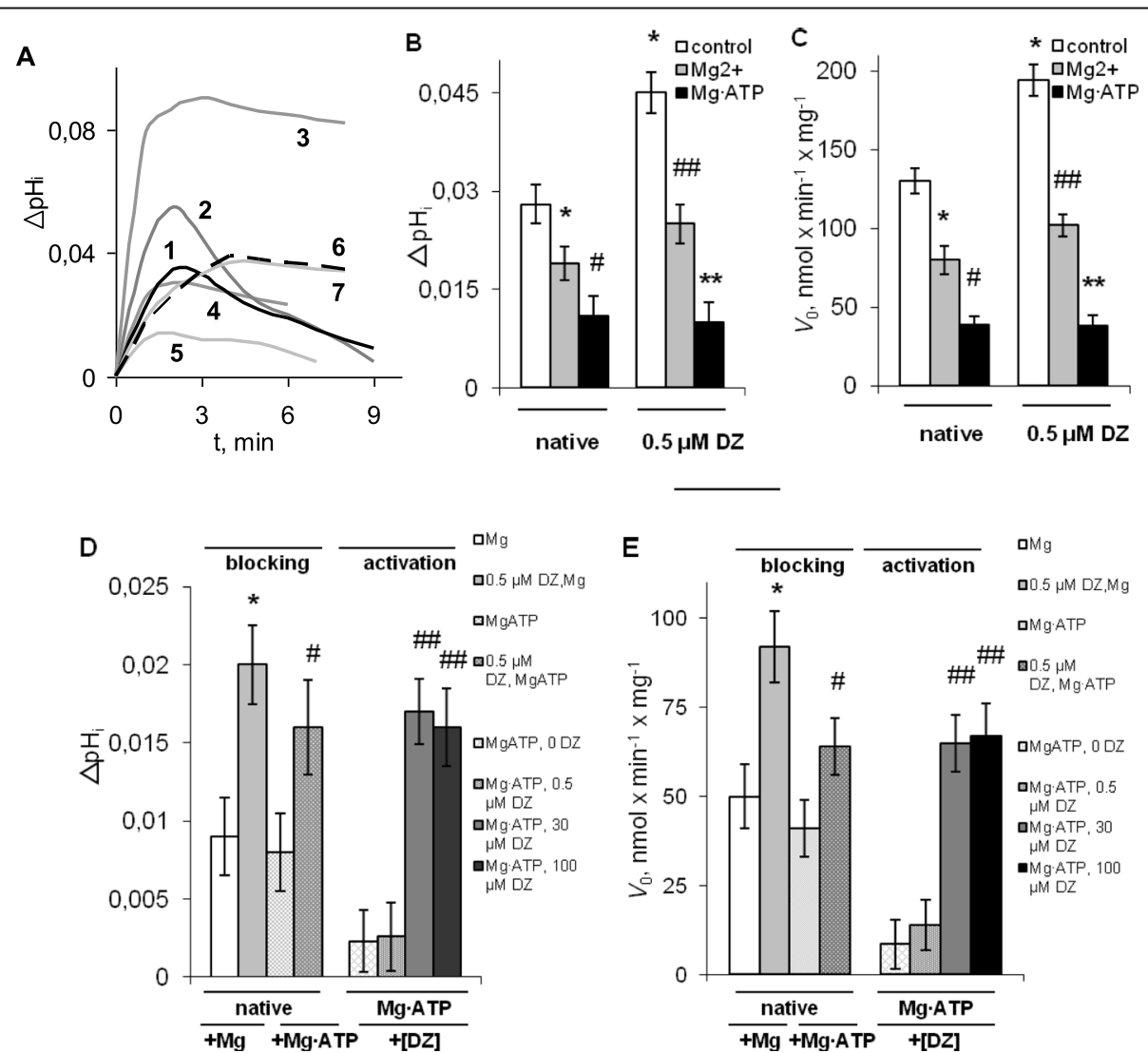

Fig. 3 The effect of diazoxide on matrix $\mathrm{pH}$ and $V_{0}$ of $\mathrm{K}^{+}$uptake, in rat liver mitochondria. a - The typical changes in matrix $\mathrm{pH}(\Delta \mathrm{pH})$ in standard incubation medium with following additions: DZ at 0, 0.5, $100 \mu \mathrm{M}$ (1-3); $0.5 \mu \mathrm{M} \mathrm{DZ,} 1 \mathrm{mM} \mathrm{Mg}{ }^{2+}$ (4); Mg.ATP and DZ added at 0.5 (5), 30 (6) and $100 \mu \mathrm{M}(7) ; \mathbf{b}, \mathbf{c}$ - the changes in $\Delta \mathrm{pH}_{\mathrm{i}}$ and $V_{0}$ of $\mathrm{K}^{+}$uptake after sequential blockage of $\mathrm{K}^{+}$transport by $\mathrm{Mg}^{2+}$ and $\mathrm{Mg} \cdot \mathrm{ATP}$ in the absence (native mitochondria) and the presence of $0.5 \mu \mathrm{M} \mathrm{DZ} ; \mathbf{d}$, e - the shares of ATP-sensitive and ATP-insensitive $\mathrm{K}^{+}$transport in $\Delta \mathrm{pH}$ and $V_{0}$ of $\mathrm{K}^{+}$ uptake found from the blockage of $\mathrm{K}^{+}$transport by $\mathrm{Mg}^{2+}$ and ATP in native mitochondria $(-\mathrm{Mg} \cdot \mathrm{ATP})$ and the activation of mK $\mathrm{ATP}^{-C h a n n e l}$ in the presence of Mg.ATP (+Mg.ATP); DZ was added at $0.5 \mu \mathrm{M}(-\mathrm{Mg} \cdot \mathrm{ATP}) ; 0.5,30$ and $100 \mu \mathrm{M}(+\mathrm{Mg} \cdot \mathrm{ATP})$. Additions are shown in the legend. M $\pm \mathrm{m}$, $n=6 ; \mathbf{b}, \mathbf{c}^{*}{ }^{*}-\mathrm{P}<0.05$ vs control (0 DZ); \# - P $<0.05$ vs. Mg2+; \#\# - P<0.01 vs. $0.5 \mu \mathrm{M} \mathrm{DZ;}{ }^{* *}-\mathrm{P}<0.01$ vs. Mg ${ }^{2+}, 0.5 \mu \mathrm{M} D Z ; \mathrm{D}, \mathrm{E}:{ }^{*}-\mathrm{P}<0.05$ vs. $\mathrm{Mg}^{2+}$ (native); \# $-\mathrm{P}<0.05$ vs. MgATP (native) \#\# - $\mathrm{P}<0.01$ vs. MgATP, $0.5 \mu \mathrm{M} D Z$ 
channel activity obtained with $30 \mu \mathrm{M}$ diazoxide in the presence of $\mathrm{Mg} \cdot \mathrm{ATP}, \sim 65 \mathrm{nmol} \cdot \mathrm{min}^{-1} \cdot \mathrm{mg}^{-1}$, with related changes in $\mathrm{pH}_{\mathrm{i}}$ by $\sim 0.015$ units (Fig. 3d, e). Further increase of diazoxide concentration up to $100 \mu \mathrm{M}$ failed to increase the channel activity anymore (Fig. 3a, 6-7; $3 d, e)$, which was similar to oxygen consumption and absorbance assays.

Observed increase in state 4 oxygen consumption (Fig. 1 a) was in line with the notion of the activation of potassium cycle $[13,14]$. To ascertain the ability of diazoxide to stimulate potassium cycling in sub-micromolar concentration area, we conducted the quantitative estimation of the effect of diazoxide on $\mathrm{K}^{+} / \mathrm{H}^{+}$-exchange in liver mitochondria.

\section{The effect of diazoxide on mitochondrial $\mathrm{K}^{+} / \mathrm{H}^{+}$-exchange}

In agreement with the published data [22] the elevation of matrix $\mathrm{pH}$, caused by potassium uptake from standard incubation medium, typically was followed by matrix acidification (Fig. 3a, 1-3, Fig. 3a Suppl) and matrix contraction (Fig. 3b Suppl) which reflected the activity of $\mathrm{K}^{+} / \mathrm{H}^{+}$-exchanger. Proton transport was completely blocked by specific inhibitor of $\mathrm{K}^{+} / \mathrm{H}^{+}$-exchanger quinine (Fig. 3a Suppl). Both $\mathrm{H}^{+}$influx and matrix contraction were activated by diazoxide (Figs. 3a; 3a, b Suppl), which proved the activation of $\mathrm{K}^{+} / \mathrm{H}^{+}$-exchange and was confirmed further by the direct observation of $\mathrm{K}^{+}$transport with the probe PBFI $^{1}$ (Fig. 3c, d, Suppl).

Uptake and efflux of $\mathrm{K}^{+}$were accompanied by the increase and the decrease in BCECF and PBFI fluorescence. As it was observed, DZ accelerated both phases of $\mathrm{K}^{+}$cycle (Fig. 3a; Fig. 3c, d, Suppl).

Quinine blocked $\mathrm{K}^{+} / \mathrm{H}^{+}$-exchange independent on the presence of diazoxide (Fig. 3a Suppl), which was in line with the notion that $\mathrm{K}^{+} / \mathrm{H}^{+}$-exchange was the only pathway of $\mathrm{K}^{+}$efflux from energized mitochondria under the conditions of our experiment. In the presence of quinine no changes in BCECF fluorescence after $\mathrm{K}^{+}$uptake was observed (Fig. 3a Suppl), which allowed quantitative estimation of $\mathrm{K}^{+} / \mathrm{H}^{+}$-exchanger activity directly from proton transport data [24]. In support of our earlier results based on absorbance measurements showing mitochondrial contraction under the same conditions ([18] and Fig. 3b Suppl), the addition of diazoxide at $\leq 0.5 \mu \mathrm{M}$ in the absence of Mg.ATP resulted in the activation of $\mathrm{K}^{+} /$ $\mathrm{H}^{+}$-exchange, as showed observed changes in kinetics of proton transport (Fig. 3a, 1, 2). Initial rate of quininesensitive potassium efflux was reliably increased by $0.5 \mu \mathrm{M}$ of diazoxide from $23 \mathrm{nmol} \cdot \mathrm{min}^{-1} \cdot \mathrm{mg}^{-1}$ in control to maximal value of $34 \mathrm{nmol} \cdot \mathrm{min}^{-1} \cdot \mathrm{mg}^{-1}$. Thus

\footnotetext{
${ }^{1}$ For this purpose mitochondria were loaded with $20 \mu \mathrm{M}$ PBFI-AM for $20 \mathrm{~min}$ at room temperature. PBFI fluorescence was monitored at 345/ 485 excitation/emission wavelengths [23]. The data of two independent assays are in Fig. 3c, d Suppl.
}

activation of both phases of potassium cycle (Fig. 3c, d, Suppl) well agreed with maximal stimulation of state 4 respiration by diazoxide on the same sub-micromolar concentration scale. With the rise of diazoxide concentration above $\sim 0.5 \mu \mathrm{M}$ no further activation of $\mathrm{K}^{+} / \mathrm{H}^{+}$exchange was observed [18], and even suppression of $\mathrm{K}^{+} / \mathrm{H}^{+}$-exchange by the high micromolar concentrations of the drug was observed (Fig. 3a, 3).

$\mathrm{Mg}^{2+}$ and Mg.ATP dramatically suppressed the activity of quinine-sensitive $\mathrm{K}^{+} / \mathrm{H}^{+}$-exchange (Fig. 3a, 4-7; Fig. 3a, Suppl.), consistent with the notion of the blocking of $\mathrm{K}^{+} /$ $\mathrm{H}^{+}$-exchanger by $\mathrm{Mg}^{2+}$ ions [13]. This could explain the absence of any apparent effect of diazoxide on $\mathrm{K}^{+} / \mathrm{H}^{+}$-exchange in the presence of $\mathrm{Mg}^{2+}$ and Mg.ATP. Thus, the blockage of $\mathrm{K}^{+}$uptake by successive additions of $\mathrm{Mg}^{2+}$ and Mg.ATP, together with the inhibition of $\mathrm{K}^{+} / \mathrm{H}^{+}$-exchange by $\mathrm{Mg}^{2+}$ eventually resulted in a strong suppression of potassium cycle.

\section{Non-specific effect of diazoxide on potassium transport}

Similar to absorbance assays (Fig. 2a, b) gradual elevation of $\mathrm{pH}_{\mathrm{i}}$ by increasing concentrations of diazoxide (from 0.5 to $100 \mu \mathrm{M})$ in the absence of Mg.ATP indicated gradual increase of potassium uptake into matrix (Fig. 3a, 1-3). The sequential blockage of $\mathrm{K}^{+}$transport by $\mathrm{Mg}^{2+}$ and Mg.ATP allowed us observe that in native mitochondria diazoxide reliably activated a transport constituent sensitive to the blockage by $\mathrm{Mg}^{2+}$, which could be identified as ATP-insensitive $\mathrm{K}^{+}$uptake (Fig. 3d, e).

Unlike $\mathrm{mK}_{\mathrm{ATP}}$-channel, ATP-insensitive potassium transport was not restored by diazoxide in the presence of $\mathrm{Mg}^{2+}$ or Mg.ATP. In fact, in the presence of Mg.ATP diazoxide selectively restored only $\mathrm{mK}_{\mathrm{ATP}}$-channel activity (Figs. 2b, 3d, e), which was proven by the complete blockage of the activated channel by glibenclamide and 5 -HD (Figs. 1d, 2b). Since in the presence of Mg.ATP increase in diazoxide concentration starting from $\sim 30 \mu \mathrm{M}$ up to high micromolar level had no more effect on $\mathrm{mK}_{\mathrm{ATP}}$-channel activity (Fig. $2 \mathrm{~b}, 3 \mathrm{~d}$, e), we came to the conclusion that the elevation of total potassium uptake in native mitochondria under high diazoxide concentrations, observed by absorbance (Fig. 2a, b) and BCECF fluorescence measurements (Fig. 3a, 1-3), occurred at the cost of ATP-insensitive potassium uptake. Proportion of ATP-insensitive to ATP-sensitive potassium transport (blocked respectively by $\mathrm{Mg}^{2+}$ and Mg.ATP) increased with the rise in diazoxide concentration, and starting from $\sim 1: 1$ in submicromolar concentration area (Fig. 3d, e), reached $\sim 3: 1$ at $100 \mu \mathrm{M}$ of the drug (Fig. 3a, 3 vs. $3 \mathrm{~d}, \mathrm{MgATP}, 100 \mu \mathrm{M}$ diazoxide). So, obtained results unambiguously indicated the ability of diazoxide to activate an ATP-insensitive potassium transport, which under experimental conditions was irreversibly blocked by $\mathrm{Mg}^{2+}$, and consequently, by Mg.ATP. 
Bioenergetic effects of diazoxide in rat liver mitochondria Uncoupling of mitochondrial respiration by diazoxide on sub-micromolar scale

As we have shown, on sub-micromolar concentration level diazoxide was effective in the activation of potassium cycle due to the enhancement of total $\mathrm{K}^{+}$uptake and the activation of $\mathrm{K}^{+} / \mathrm{H}^{+}$exchange. Potassium cycling is energy-dissipating process, thus to assess uncoupling effect of potassium cycle stimulated by diazoxide, the respiratory control ratio (RCR) was found at concentrations efficient in stimulation of state 4 respiration. In Fig. $4 \mathrm{a}$ obtained RCR values were plotted against the rate of state 4 respiration stimulated by increasing concentrations of diazoxide. RCR decrease with the increase in state 4 oxygen consumption indicated mitochondrial uncoupling (Fig. 4a, black circles). With the aim to ascertain that uncoupling by diazoxide resulted from the activation of potassium transport, we compared the effect of diazoxide to the effect of $\mathrm{K}^{+}$-ionophore, valinomycin. Based on RCR ratios, the same respiration stimulation by diazoxide and valinomycin resulted in similar mitochondrial uncoupling (Fig. 4a, white circles). This allowed the conclusion that uncoupling of the respiratory chain by diazoxide was caused by the stimulation of potassium cycle resulting from the activation of potassium uptake in mitochondria, without any non-specific effect.

Despite the lack of diazoxide selectivity as $\mathrm{mK}_{\mathrm{ATP}}{ }^{-}$ channel opener in the absence of Mg.ATP, the estimation of the share of $\mathrm{mK}_{\mathrm{ATP}}$-channel in state 4 oxygen consumption enabled us to assess partial contribution of the channel to mitochondrial uncoupling. Thus, from Fig. $4 \mathrm{a}$, and the share of $\mathrm{mK}_{\mathrm{ATP}}$-channel in state 4 respiration found earlier $\left(\sim 8 \mathrm{ng}\right.$-at. O $\left.\cdot \mathrm{min}^{-1} \cdot \mathrm{mg}^{-1}\right)$, we obtained that maximal $\mathrm{mK}_{\mathrm{ATP}}$-channel activity stimulated by diazoxide should reduce RCR in tightly coupled mitochondria by $\sim 3.5$ units, i.e. from $\sim 7.5$ to $\sim 4.0$, which was consistent with the notion of mild uncoupling of the respiratory chain [13].

\section{$m K_{A T P}$-channel opening by diazoxide on sub-micromolar level reduces ROS formation in liver mitochondria}

To find the effect of diazoxide on ROS production in liver mitochondria, DCF fluorescence was monitored under steady-state conditions related to state 4 respiration. Quasi linear increase of fluorescence under these conditions was observed within $\sim 5 \mathrm{~min}$ since the
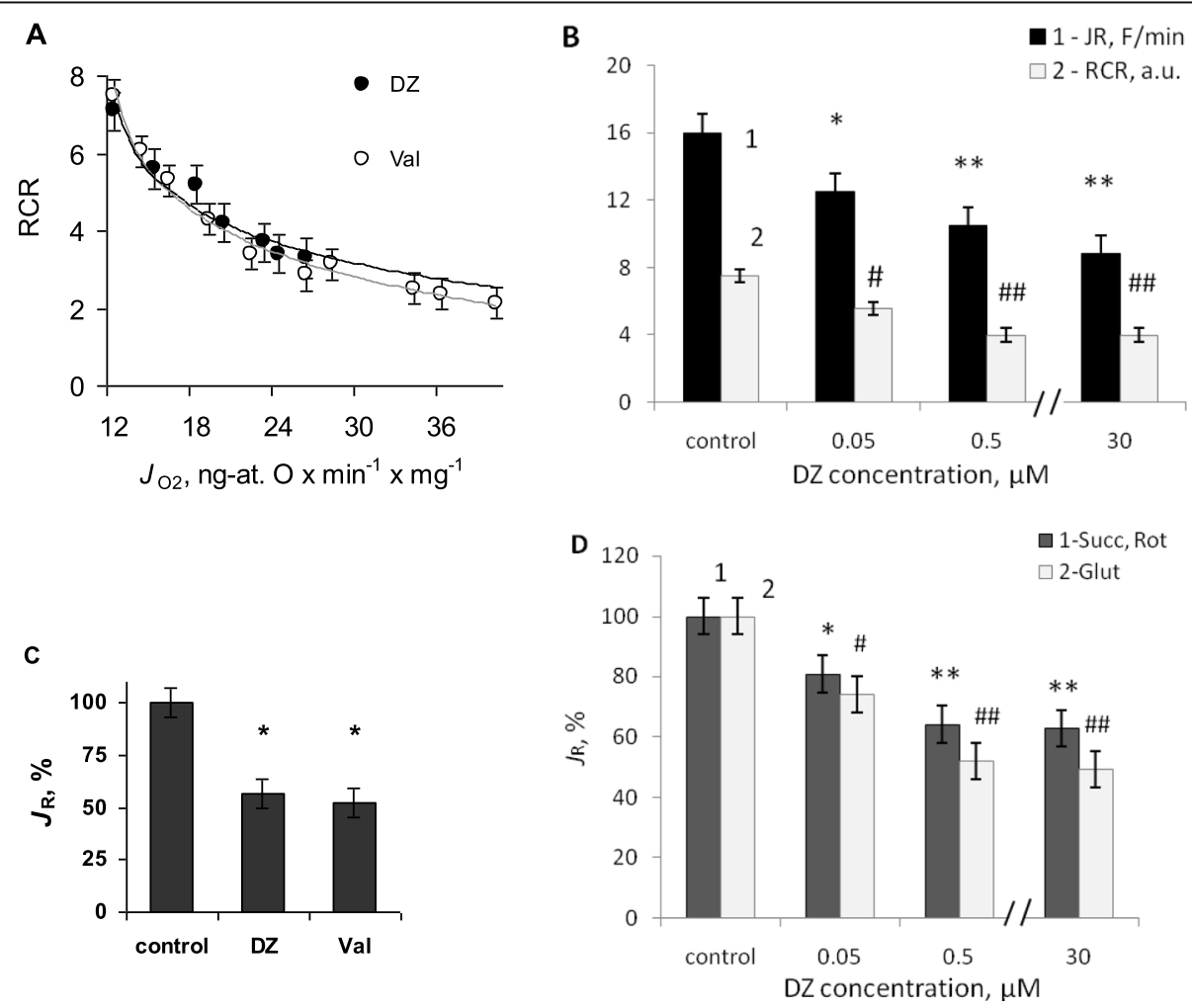

Fig. 4 Bioenergetic effects of diazoxide: respiratory uncoupling (a) and suppression of ROS production (b-d). $\mathbf{a}$ - To assess uncoupling effect respiratory control ratio $(R C R)$ was plotted against the rate of state 4 respiration $\left(J_{\mathrm{O}_{2}}\right)$ stimulated by diazoxide and valinomycin; $\mathbf{b}$ - the rates of oxidant formation found as the increments in DCF fluorescence (1) and mitochondrial uncoupling found as RCR (2) against DZ concentration, $\mu \mathrm{M} ; \mathbf{c}$ - the rates of ROS formation in tightly coupled mitochondria (RCR 7.5)), and under respiratory uncoupling by diazoxide and valinomycin (RCR 4.0); $\mathbf{d}$ - the rates of oxidant formation in mitochondria respiring on succinate (1) and glutamate (2). $M \pm m, n=4 ; B-D:{ }^{*}, \#-P<0.05$ vs.0 $D Z ;{ }^{* *}, \# \#-P<0.05$ vs. $0.05 \mu \mathrm{M} \mathrm{DZ}$ 
addition of mitochondria (Fig. 4a, b, Suppl). In nonrespiring mitochondria DCF gave very low fluorescence signal, which apparently increased after the addition of the respiratory substrates (Fig. 4 a, b, Suppl), thus DCF fluorescence under experimental conditions largely reflected ROS formation by the respiratory chain. The increment of DCF fluorescence with time $\left(J_{R}\right)$ was plotted against diazoxide concentration (Fig. 4b).

In sub-micromolar concentrations, capable of activation of ATP-sensitive $\mathrm{K}^{+}$transport without apparent mitochondrial depolarization, diazoxide in the absence of Mg.ATP reliably reduced the rate of DCF oxidation as compared to control (tightly coupled mitochondria, RCR 7.5 (Fig. 4b; Fig. 4 Suppl), which indicated the suppression of ROS production. Inhibition of the oxidants formation in the respiratory chain well correlated with the uncoupling effect of diazoxide on mitochondrial respiration (Fig. 4b). Considering that respiratory uncoupling was caused by the activation of potassium transport (Fig. 4a), we examined whether mitochondrial ROS production was similarly affected by valinomycin. As we observed, the same uncoupling by valinomycin (at RCR ratio of 4.0 units) similarly suppressed ROS production (Fig. 4 c). To ascertain our conclusion about the reduction of ROS production by diazoxide using glutamate as the respiratory substrate, we conducted the same study with succinate adding rotenone to abolish the reverse electron transport. Results obtained on the succinate-driven respiration confirmed the inhibition of ROS formation in parallel with the activation of $\mathrm{K}^{+}$ cycle (Fig. 4d). Reduction of ROS formation by diazoxide was as well observed after the addition of antimycin A to block electron transport at Complex III (the conditions known to promote ROS production in mitochondria (Fig. 4b Suppl)).

In the literature, ability of diazoxide to interfere with DCF fluorescence and increase its intensity independent of $\mathrm{mK}_{\mathrm{ATP}}$-channel opening was shown [25]. However, in our work, on the contrary, DCF fluorescence was decreased by diazoxide. Besides, referenced work reported the effects of high micromolar concentrations of the drug; while in our work low sub-micromolar concentrations of diazoxide were used. As we have shown, DCF fluorescence was reliably reduced by as low as $0.05-0.5 \mu \mathrm{M}$ of diazoxide, which was in line with the activation of $\mathrm{K}^{+}$cycle (Fig. 4a, b). Close effect obtained with valinomycin under similar uncoupling conditions, independent of diazoxide (Fig. 4c) confirmed the conclusion that the decrease in DCF fluorescence can be explained by the reduction of ROS formation in mitochondria. Thus, we came to the conclusion that ROS production in native liver mitochondria in the absence of Mg.ATP was highly sensitive to low sub-micromolar diazoxide concentrations because of $\mathrm{mK}_{\mathrm{ATP}}$-channel opening, activation of potassium cycling and respiratory uncoupling within the same concentration range.

\section{Discussion}

\section{The effect of diazoxide on $\mathrm{mK}_{\mathrm{ATP}}$-channel activity}

To study the effect of diazoxide on $\mathrm{K}^{+}$transport, two sets of experiments were conducted: in the absence and the presence of Mg.ATP. To ascertain specific activation of $\mathrm{mK}_{\mathrm{ATP}}$-channel by submicromolar diazoxide concentrations $(\leq 0.5 \mu \mathrm{M})$, potassium transport was sequentially blocked by $\mathrm{Mg}^{2+}$ and ATP. With the aim to establish the share of $\mathrm{mK}_{\mathrm{ATP}}$-channel in total $\mathrm{K}^{+}$uptake, ATPsensitive $\mathrm{K}^{+}$transport was activated by micromolar diazoxide concentrations in the presence of Mg.ATP in agreement with [17] and then blocked by glibenclamide and 5-HD to prove $\mathrm{mK}_{\mathrm{ATP}}$-channel opening. Without MgATP, diazoxide exhibited potent activation of $\mathrm{K}^{+}$uptake. While in the presence of Mg.ATP $\mathrm{mK}_{\mathrm{ATP}}$-channel was routinely activated by micromolar diazoxide concentrations (consistent with literary data), stepwise activation of $\mathrm{K}^{+}$uptake by increasing concentrations of the drug in the absence of Mg.ATP revealed high sensitivity of $\mathrm{mK}_{\mathrm{ATP}^{-}}$ channel to this opener, with full activation at $\leq 0.5 \mu \mathrm{M}$. Additionally, parallel activation of ATP-insensitive potassium uptake was found that increased with the rise of diazoxide concentration up to $100 \mu \mathrm{M}$.

Worth mention, that main limitation of our study was the use of indirect methods to assess $\mathrm{mK}_{\mathrm{ATP}}$-channel activity and inability of molecular identification of ATPsensitive $\mathrm{K}^{+}$transport sensitive to diazoxide in the absence of MgATP. However, an estimate of native $\mathrm{mK}_{\mathrm{ATP}}$-channel activity $\left(\sim 40 \mathrm{nmol} \mathrm{K} \cdot \mathrm{min}^{-1} \cdot \mathrm{mg}^{-1}\right)$ using respiration and proton transport assays well agreed with the assessment of $\mathrm{mK}_{\mathrm{ATP}}$-channel activity with $\mathrm{K}^{+}$-selective electrode (45.0 \pm $5.0 \mathrm{nmol} \mathrm{K}^{+} \cdot \mathrm{min}^{-1} \cdot \mathrm{mg}^{-1}$ ) by monitoring ATP-sensitive potassium efflux from deenergized mitochondria [26]. Also, sequential blockage of $\mathrm{K}^{+}$transport by $\mathrm{Mg}^{2+}$ and ATP proved the activation of native $\mathrm{mK}_{\mathrm{ATP}}$-channel by diazoxide. In the presence of MgATP, which blocked $\mathrm{mK}_{\mathrm{ATP}}$-channel, no additional blocking of $\mathrm{K}^{+}$transport by $\mathrm{mK}_{\mathrm{ATP}}$-channel blockers glibenclamide and 5-HD was observed (Fig. 1d). This proves that ATP-sensitive $\mathrm{K}^{+}$transport, activated by diazoxide and blocked by MgATP, can be ascribed to native $\mathrm{mK}_{\mathrm{ATP}}$-channel activity in rat liver mitochondria.

Mg.ATP was generally thought to be indispensable for $\mathrm{mK}_{\mathrm{ATP}}$-channel activation by potassium channels openers, but in support of our findings, literary data as well showed susceptibility of $\mathrm{mK}_{\mathrm{ATP}}$-channel to the activation by diazoxide and the blockage by glibenclamide and 5-HD in the absence of Mg.ATP [27, 28]. However, unlike the works referred to above, which used high micromolar diazoxide concentrations, we proved full stimulation of ATP-sensitive $\mathrm{K}^{+}$transport on sub-micromolar scale. The sensitivity of native $\mathrm{mK}_{\mathrm{ATP}}$-channel of rat liver mitochondria to diazoxide was close to literary data on isolated reconstituted $\mathrm{mK}_{\mathrm{ATP}}$-channel with apparent activation constant $K_{\mathrm{a}} \sim 350$ 
$\mathrm{nM}$ [12]. In our work, activation of the channel in the presence of Mg.ATP, even at high micromolar diazoxide concentrations $(100 \mu \mathrm{M})$, could not exceed activity reached with native channel at submicromolar concentrations of the drug in the absence of Mg.ATP (Fig. 2a, b; Fig. 3d, e). Thus our experiments allow us hypothesize that $\mathrm{mK}_{\mathrm{ATP}}{ }^{-}$ channel might comprise the site(s) accessible to pharmacologic modulators and responsible for the channel activation in the absence of Mg.ATP.

\section{Side effect of diazoxide on potassium uptake in rat liver mitochondria}

In the literature several side effects of diazoxide were reported, such as protonophoric uncoupling [15], respiratory inhibition [16], interference with flavoprotein oxidation [29] and DCF fluorescence [25]. The lack of diazoxide selectivity as $\mathrm{mK}_{\mathrm{ATP}}$-channel opener found in our work, which was shown in parallel activation of ATP-insensitive potassium transport, was novel not described earlier side effect of this drug. ATP-insensitive potassium transport rose gradually with the increase of diazoxide concentration up to high micromolar level. Accordingly, total potassium uptake under the action of diazoxide increased because of the increase in ATPinsensitive component (Figs. 2a, 3a). This resulted in the reduction of the ratio of ATP-sensitive to ATP-insensitive potassium uptake with the rise of diazoxide concentration. Unlike ATP-sensitive potassium transport, ATP-insensitive one could not be restored by diazoxide and its blockage by $\mathrm{Mg}^{2+}$ and Mg.ATP, was irreversible under experimental conditions.

For the most part unspecific actions of diazoxide reported in the literature [10] were observed at high micromolar concentrations $(\geq 50-100 \mu \mathrm{M})$, and the side effects of diazoxide were independent of its action on potassium transport. Unlike the published data, side effect of diazoxide found in our work was the activation of ATP-insensitive potassium transport, starting from low sub-micromolar concentrations in the absence of $\mathrm{Mg}^{2+}$ and ATP. The nature of this transport remains yet to be established. Thus, the ability of diazoxide to activate other than $\mathrm{K}_{\mathrm{ATP}}$ channels, $\mathrm{BK}_{\mathrm{Ca}}$ and $\mathrm{Kv}$ channels, of plasma membrane of smooth muscle cells was reported [30]. But leaving aside several types of potassium channels already described in mitochondria (e.g. in the review [11]), even in the case of $\mathrm{mK}_{\mathrm{ATP}}$ channel, uncertainty still exists about molecular mechanism of its response to diazoxide [31, 32].

Generally, it is known that $\mathrm{K}_{\mathrm{ATP}}$-channels openers bind to the receptor SUR subunits of the channel, which possesses MgATPase activity. So, the presence of MgATP is considered to be indispensable for $\mathrm{K}_{\mathrm{ATP}}$-channel opening [12]. Meanwhile, none of the recent hypotheses about molecular nature of $\mathrm{K}^{+}$conductant subunit of $\mathrm{mK}_{\mathrm{ATP}}{ }^{-}$ channel could satisfactory explain the mechanism of

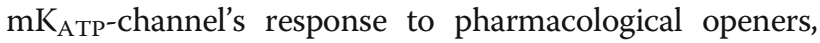
such as diazoxide [31, 32]. As it was reported in earlier studies, in the heart, Kir6.2 was dispensable for the $\mathrm{K}^{+}$ conductance stimulated by diazoxide [31]. Also, none of ROMK isoforms (Kir1.1, Kir3.1, and Kir3.4) proposed as $\mathrm{K}^{+}$conductant subunit of $\mathrm{mK}_{\mathrm{ATP}}$-channel $[33,34]$ was responsible for diazoxide-induced swelling of cardiac mitochondria [32]. These studies indicated that $\mathrm{K}^{+}$conductant subunit of $\mathrm{mK}_{\mathrm{ATP}}$-channel didn't belong to either Kir6.x, or Kir1.x channels, but molecular nature of the $\mathrm{K}^{+}$pore of $\mathrm{mK}_{\mathrm{ATP}}$-channel remained elusive.

However, quite recently, molecular composition of $\mathrm{mK}_{\mathrm{ATP}}$-channel was disclosed, based on combined proteomics, biophysical and biochemical studies [35]. This work principally confirmed the knowledge on molecular architecture of $\mathrm{mK}_{\mathrm{ATP}}$-channel as an octameric multiprotein complex composed of four $\mathrm{K}^{+}$conductant and four receptor subunits, named MITOK and MITOSUR respectively. Also, it was confirmed that $\mathrm{K}^{+}$conductant subunit of $\mathrm{mK}_{\mathrm{ATP}}$-channel performs a number of vital functions, such as volume regulation, maintenance of mitochondrial membrane potential, regulation of ATP synthesis and $\mathrm{Ca}^{2+}$ transport [35]. Genetic deletion of MITOK caused instability of $\Delta \Psi \mathrm{m}$, suppression of phosphorylation, and loss of cardioprotective effect of diazoxide [35].

Meanwhile, novel discovery of $\mathrm{mK}_{\mathrm{ATP}}$-channel put novel questions about the functions of Kir6.x and Kir1.x channels, which expression was found in cardiac, brain, and other tissues [33]. Also, still much controversy remains about the properties of $\mathrm{mK}_{\mathrm{ATP}}$-channel, their unexplained diversity in different preparations (mitoplasts, proteoliposomes, isolated mitochondria), and uncertainty about the direct and off-target effects of pharmacological modulators of $\mathrm{mK}_{\mathrm{ATP}}$-channel. The disclosure of molecular nature of $\mathrm{mK}_{\mathrm{ATP}}$-channel will help in filling numerous gaps in the understanding of the properties of $\mathrm{mK}_{\mathrm{ATP}}$-channels, their physiological functions, and molecular mechanisms of their interactions with pharmacological modulators.

Thus, to explain observed effects of diazoxide on ATP-sensitive $\mathrm{K}^{+}$transport, we cannot rule out some particular mode of the activation of $\mathrm{mK}_{\mathrm{ATP}}$-channel in the absence of Mg.ATP. Also, the blockage of ATPinsensitive inward potassium transport by $\mathrm{Mg}^{2+}$ alone, in the absence of ATP implies the involvement of some other types of potassium channels in the activation of $\mathrm{K}^{+}$ transport by diazoxide.

The inability of diazoxide to stimulate state 4 respiration at concentrations above $\sim 0.5 \mu \mathrm{M}$ (Fig. 1a), differed from our transport assays, which showed gradual increase of $\mathrm{K}^{+}$ uptake with the increase of diazoxide concentration. Based on proton transport study, we observed that lack in 
respiration stimulation with the increase in diazoxide concentration above a certain threshold well coincided with the failure of this drug in stimulation of $\mathrm{K}^{+} / \mathrm{H}^{+}$-exchange at concentrations above $\sim 0.5 \mu \mathrm{M}$. Moreover, a suppression of $\mathrm{K}^{+} / \mathrm{H}^{+}$-exchange was observed with the increase of diazoxide concentration to high micromolar level (Fig. 3a, 3). However, on sub-micromolar scale, "mild" uncoupling of respiratory chain by diazoxide was shown to result directly from the activation of potassium transport, which was confirmed by close proximity of the effects of diazoxide and $\mathrm{K}^{+}$ionophore valinomycin (Fig. 4a).

\section{Suppression of ROS production by diazoxide in liver mitochondria}

The modulation of ROS production by diazoxide and its cytoprotective effects was shown in multiple studies. However, these works used high diazoxide concentrations in the presence of MgATP [22]. The aim of this work was to examine the effects of low diazoxide concentrations, capable of full stimulation of $\mathrm{mK}_{\mathrm{ATP}}$-channel activity without MgATP, on mitochondrial ROS production. As we have shown in this work, rat liver mitochondria exhibited high sensitivity of ROS production to diazoxide at sub-micromolar concentration level explained by high sensitivity of potassium transport to this drug.

It worth mention, that published data showed much controversy regarding the effect of diazoxide and other $\mathrm{mK}_{\mathrm{ATP}}{ }^{-}$ channel openers on ROS production in different tissues. While many authors reported the increase of ROS production caused by $\mathrm{mK}_{\mathrm{ATP}}$-channels opening $[1,2,22,36]$, other studies showed the decrease of free radical formation caused either by diazoxide, or $\mathrm{mK}_{\mathrm{ATP}}$-channel opening under physiological and pathophysiological conditions in the heart [3, 7], brain [3] and liver [6]. But while in the brain the decrease of ROS production can be explained by appreciable mitochondrial depolarization due to potassium transport [37], in heart and liver $\mathrm{mK}_{\mathrm{ATP}}$-channel opening was unable to cause depolarization sensed by commonly used techniques such as potentiometry or fluorescent probes [13]. Thus it was proposed that the reduction of ROS production caused by $\mathrm{mK}_{\mathrm{ATP}}$-channels openers could be explained by mild mitochondrial uncoupling and minor depolarizations $(\sim 2-5 \mathrm{mV})$ caused by ATP-sensitive $\mathrm{K}^{+}$uptake $[6,25]$. While we did not observe any apparent effect of diazoxide on $\Delta \Psi_{\mathrm{m}}$, our data in line with this assumption, showed a good correlation between mitochondrial uncoupling and the decrease of ROS formation in the course of forward electron transport driven either by glutamate or succinate (Fig. 4b-d). Thus minor fluctuations in $\Delta \Psi_{\mathrm{m}}$ caused by the uncoupling of the respiratory chain remain a plausible explanation for the observed decrease of ROS production by sub-micromolar concentrations of diazoxide in liver mitochondria under several conditions examined in this work (Fig. 4 Suppl). Worth notion, that the mechanisms controlling ROS production in mitochondria exhibited large differences dependent on the cell types [38]. So, the mechanisms in which diazoxide affects ROS production as well can show cell-specificity. However, detailed study is required to answer this issue.

Similar to what was observed by Garlid's group [22], in our work matrix pH was increased by diazoxide (Fig. 3a, $1,2)$, which is known to promote ROS production [39]. But unlike Garlid's works, in our study diazoxide suppressed ROS production within the timeframes coincident with the elevation of matrix pH (Fig. 3a, 1, 2; Fig. 4a, b Suppl). In our case, this difference can be explained by strong activation of $\mathrm{K}^{+} / \mathrm{H}^{+}$-exchange, and mitochondrial uncoupling caused by the activation of $\mathrm{K}^{+}$cycle, which was suppressed by MgATP in the works of Garlid's group. As we observed, in the presence of MgATP diazoxide in micromolar concentrations increased $\mathrm{K}^{+}$uptake by the opening of $\mathrm{mK}_{\mathrm{ATP}}$-channel, but failed to restore $\mathrm{K}^{+} / \mathrm{H}^{+}$exchange in mitochondria (Fig. 3a, 6, 7). Matrix alcalinization caused by the blocking of $\mathrm{K}^{+} / \mathrm{H}^{+}$-exchange in the presence of MgATP could promote the elevation of ROS production by $\mathrm{mK}_{\mathrm{ATP}}$-channel openers observed in Garlid's works $[1,22]$.

\section{Conclusions}

In this work using indirect methods to study $\mathrm{K}^{+}$transport and $\mathrm{mK}_{\mathrm{ATP}}$-channel actiuvity, we disclosed novel aspects of native $\mathrm{mK}_{\mathrm{ATP}}$-channel opening by diazoxide, and the ability of this drug to increase ATP-insensitive potassium transport in mitochondria in the absence of Mg.ATP. Based on the experiments we established the following: 1) high sensitivity of native $\mathrm{mK}_{\mathrm{ATP}}$-channel to the activation by diazoxide with maximal effect at $\leq 0.5 \mu \mathrm{M}$, which strongly affects mitochondrial bioenergetics on submicromolar scale; 2) strong activation of ATP-insensitive potassium transport, which was novel, not described earlier side effect of the drug; 3 ) high sensitivity of state 4 oxygen consumption to diazoxide at $\leq 0.5 \mu \mathrm{M}$ caused by the activation of potassium cycle in the absence of MgATP and 4) suppression of ROS production caused by the activation of $\mathrm{K}^{+}$cycle and mitochondrial uncoupling within the same sub-micromolar concentration range. Based on the experiments, we hypothesized the presence of high affinity sites for diazoxide binding. Their possible screening by MgATP shifts $\mathrm{mK}_{\mathrm{ATP}}$-channel affinity to diazoxide from submicromolar to micromolar concentration scale.

Mitochondrial potassium channels, together with uncoupling proteins represent potent uncoupling machinery [14], which protects mitochondria from ROS overproduction and $\mathrm{Ca}^{2+}$ overload. The results obtained in our work make ground for using diazoxide as an effective pharmacological tool for the modulation of mitochondrial bioenergetics and ROS production. High sensitivity of 
$\mathrm{mK}_{\mathrm{ATP}}$-channel to diazoxide in the absence of ATP observed in this study allows us hypothesize that under pathophysiological states and conditions marked by ATP deficiency (such as hypoxia and ischemia) affinity of $\mathrm{mK}_{\mathrm{ATP}}$-channel to this drug can increase several times, which might contribute to the high effectiveness of diazoxide in cardio- and neuroprotection. This may be of relevance for health care practice, based on the report of successful application of sub-maximal doses of diazoxide for neuroprotection published in the literature [40].

Molecular mechanism of $\mathrm{mK}_{\mathrm{ATP}}$-channel activation by diazoxide and other $\mathrm{mK}_{\mathrm{ATP}}$-channel openers was not yet established. Our experiments reveal novel aspects of $\mathrm{mK}_{\mathrm{ATP}}$-channel interaction with diazoxide which would help bring new insight into understanding of $\mathrm{mK}_{\mathrm{ATP}}{ }^{-}$ channel properties.

\section{Methods}

For the purpose to study the effect of $\mathrm{mK}_{\mathrm{ATP}}$-channel opener diazoxide on native $\mathrm{mK}_{\mathrm{ATP}}$-channel activity, potassium transport, and potassium cycle, the study was conducted in parallel, in the absence and in the presence of MgATP. To assess the $\mathrm{mK}_{\mathrm{ATP}}$-channel activity, the channel was conventionally blocked by MgATP, opened by high micromolar concentrations of diazoxide, and repeatedly blocked by $\mathrm{mK}_{\mathrm{ATP}}$-channel blockers glibenclamide and 5-HD [17]. To assess the effect of diazoxide on $\mathrm{mK}_{\mathrm{ATP}}$-channel activity without MgATP, potassium transport was sequentially blocked by $\mathrm{Mg}^{2+}$ and ATP. ATP-sensitive part of $\mathrm{K}^{+}$transport was assumed to reflect $\mathrm{mK}_{\mathrm{ATP}}$-channel activity. The rate of ATP-sensitive $\mathrm{K}^{+}$ transport found without MgATP was compared to $\mathrm{mK}_{\mathrm{ATP}^{-}}$ channel activity obtained in the presence of MgATP.

\section{Mitochondrial preparations}

The work has been conducted in accordance with "Guide for the Care and Use of Laboratory Animals" 8th ed. Washington, DC: National Research Council of the National Academies: The National Academic Press, 2011. All procedures involving animals were approved by the Ethics Commission on Animal Experiments of A.A. Bogomoletz Institute of Physiology, NAS of Ukraine. Adult Wistar-Kyoto female rats with 180-200 g mean body weight, kept in plexiglass cages at $12 / 12-\mathrm{h}$ light/dark cycle $\left(22^{\circ} \mathrm{C}\right)$, and fed on standard diet with free access to water, were obtained from Veterinary department of AA Bogomoletz Institute of Physiology.

Prior to sacrifice, the animals were lightly anesthetized with ether inhalation and decapitated. Single animal was used in each experiment. Liver was excised and washed by cold $0.9 \% \mathrm{KCl}$ solution $\left(4{ }^{\circ} \mathrm{C}\right)$, minced and homogenized in 1:5 volume of the isolation medium: $250 \mathrm{mM}$ sucrose, $1 \mathrm{mM}$ EDTA, $20 \mathrm{mM}$ Tris- $\mathrm{HCl}$ buffer, $4{ }^{\circ} \mathrm{C}(\mathrm{pH}$ 7.2). Mitochondria were isolated by centrifugation at 700 $\mathrm{x} \mathrm{g}$ for $7 \mathrm{~min}\left(4^{\circ} \mathrm{C}\right)$. After the pellet was discarded, supernatant was centrifuged again at $11000 \times \mathrm{x}$ for 15 $\min \left(4^{\circ} \mathrm{C}\right)$. Final pellet was resuspended in a small volume of isolation medium without EDTA and stored on ice. The protein content was determined by the Lowry method.

\section{The study of oxygen consumption}

Oxygen consumption was studied polarographically in 1 $\mathrm{cm}^{3}$ closed termostated cell at $26^{\circ} \mathrm{C}$ with platinum electrode at constant stirring in standard incubation medium: $120 \mathrm{mM} \mathrm{KCl}, 0.5 \mathrm{mM}$ EDTA, $5 \mathrm{mM}$ sodium

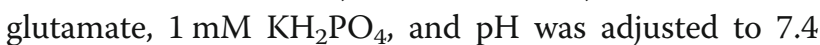
by $\mathrm{KOH}$. When necessary, $\mathrm{K}^{+}$was isotonically replaced by $\mathrm{Na}^{+}$; in the presence of $\mathrm{Mg}^{2+}$ EDTA was replaced by

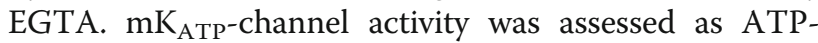
sensitive component of state 4 respiration, based on its specific blockage by Mg.ATP, reactivation by diazoxide and repeated blockage with glibenclamide and 5hydroxydecanoate, 5-HD [17]. It was found as an absolute value of respiration rate differences sensitive to the addition of ATP in the presence of $\mathrm{Mg}^{2+}$; diazoxide in the presence of Mg.ATP, or glibenclamide and 5-HD in the presence of Mg.ATP and $30 \mu \mathrm{M}$ diazoxide. When required, other additions to standard incubation medium were as follows: $\mathrm{MgCl}_{2}(1 \mathrm{mM})$, ATP $(0.3 \mathrm{mM})$, glibenclamide $(10 \mu \mathrm{M}), 5-\mathrm{HD}(100 \mu \mathrm{M})$, oligomycin $(1 \mu \mathrm{g} / \mathrm{mg}$ protein), ADP $(200 \mu \mathrm{M})$. Diazoxide was added at concentrations required. Cytochrome $c$ was added to standard incubation medium at $10 \mu \mathrm{M}$. Respiratory control ratio (RCR) was found as the ratio of state 3 to state 4 respiration rates. Final protein concentration was 1.5$2.0 \mathrm{mg} / \mathrm{ml}$.

\section{The light absorbance assay of potassium transport}

The effect of diazoxide on potassium transport was assessed spectrophotometrically by monitoring the decxrease in the absorbance of mitochondrial suspensions caused by potassium uptake and matrix swelling [17]. Absorbance was monitored at $520 \mathrm{~nm}$ in $1 \mathrm{~cm}^{3}$ cell in standard incubation medium starting from the addition of mitochondria at $1.0 \mathrm{mg} / \mathrm{ml}$. Other additions were as described above. The total absorbance change reached since the addition of mitochondria to the incubation medium was ascribed to matrix swelling. In order to assess the effects of $\mathrm{mK}_{\mathrm{ATP}}$-channel ligands on the channel activity, absorbance change differences $(\Delta \mathrm{A})$ were found as the differences in swelling amplitude sensitive to diazoxide and $\mathrm{mK}_{\mathrm{ATP}}$-channel blockers, glibenclamide and 5-HD, in the absence and the presence of Mg.ATP.

\section{The study of proton transport}

Proton transport and the change in matrix $\mathrm{pH}\left(\Delta \mathrm{pH}_{\mathrm{i}}\right)$ were assessed with $\mathrm{pH}$-sensitive fluorescent probe $2^{\prime}, 7^{\prime}$ - 
bis-(2-carboxyethyl)-5(6)-carboxyfluorescein acetoxymethyl ester (BCECF-AM) according to Brierley and Jung [24]. Briefly, mitochondria were preloaded with BCECFAM (final concentration $10 \mu \mathrm{M}$ ) and incubated $10 \mathrm{~min}$ at $37^{\circ} \mathrm{C}$, then washed from the excess dye and stored on ice $\left(4^{\circ} \mathrm{C}\right)$. After addition of aliquots of the suspension $(0.3$ $\mathrm{mg} / \mathrm{ml}$ ) to standard incubation medium, the change in BCECF fluorescence because of proton transport was recorded at the excitation/emission wavelengths 509/535 $\mathrm{nm}$. Basal fluorescence $\left(\mathrm{F}_{0}\right)$ caused by the addition of mitochondria to the incubation medium was subtracted. $F_{0}$ was found by extrapolation of kinetic curves to zero time. For the quantitative estimation of the initial rates of proton transport $\left(V_{0}\right)$ aliquots of the suspension loaded by BCECf were titrated by $\mathrm{HCl}$ in standard incubation medium in the presence of $5 \cdot 10^{-6} \mathrm{M}$ rotenone and $10^{-6}$ $\mathrm{M}$ CCCP without EDTA. The changes in matrix $\mathrm{pH}$ $\left(\Delta \mathrm{pH}_{\mathrm{i}}\right)$ were determined in parallel under the same conditions with a glass microelectrode in $1 \mathrm{~cm}^{3}$ volume of the medium. Initial rates of proton transport $\left(\mathrm{nmol} \mathrm{H}^{+} \cdot \mathrm{min}^{-1}\right.$. $\mathrm{mg}^{-1}$ ) and the values of $\Delta \mathrm{pH}_{\mathrm{i}}$ were determined from the calibration curves obtained in the absence and the presence of $\mathrm{Mg}^{2+}$ and Mg.ATP. In case of Mg.ATP free concentration of $\mathrm{H}^{+}$ions was obtained from parallel titrations with glass microelectrode measuring $\mathrm{pH}$ in the absence and the presence of Mg.ATP.

The rates of potassium transport were found from the rates of proton transport, based on the known stoichiometry of $1 \mathrm{H}^{+}: 1 \mathrm{~K}^{+} . \mathrm{K}^{+} / \mathrm{H}^{+}$exchange was assessed directly by monitoring quinine-sensitive decrease in BCECF fluorescence reflecting proton influx to the matrix [24].

\section{The detection of ROS formation in mitochondria}

To study the effect of diazoxide on ROS formation, widely used probe $2^{\prime}, 7^{\prime}$-dichlorofluorescein diacetate $\left(\mathrm{DCFH}_{2} \mathrm{DA}\right)$ was applied. This compound readily penetrates mitochondrial membranes following the concentration gradient and is deacetylated in the matrix to form membrane-impermeable non-fluorescent derivative $\mathrm{H}_{2}$ DCF $\left(2^{\prime}, 7^{\prime}\right.$-dihydrodichlorofluorescein), which is oxidized by mitochondrial ROS with the formation of highly fluorescent end product $2^{\prime}, 7^{\prime}$-dichlorofluorescein, DCF [41]. Mitochondria in stock suspension $(20 \mathrm{mg} / \mathrm{ml})$ were loaded with $200 \mu \mathrm{M}$ of $\mathrm{DCFH}_{2} \mathrm{DA}$ for $30 \mathrm{~min}$ at $37^{\circ} \mathrm{C}$ in the dark, then washed of excess probe and stored on ice $\left(4^{\circ} \mathrm{C}\right)$. After addition of mitochondria at 1 $\mathrm{mg} / \mathrm{ml}$, the increase in DCF fluorescence reflecting ROS formation was monitored over $5 \mathrm{~min}$ time interval, based on polarographic monitoring of the rate of state 4 respiration, which is inhibited with time because of gradual release of cytochrome c from mitochondria. Under the conditions when steady state rate of respiration was established, the time courses of DCF fluorescence exhibited quasi linear increase in fluorescence intensity (Fig. 4 A, B
Suppl). The rate of the increase in DCF fluorescence and the change in fluorescence intensity over the time of observation ( $3 \mathrm{~min}$ ) was assumed to reflect ROS formation in mitochondria.

\section{Chemicals}

All reagents were from Sigma-Aldrich, USA. Deionized water was used for solutions preparations.

\section{Statistical analysis}

The data were expressed as mean \pm S.D. of 4-6 independent experiments. Statistical analysis was performed based on one-way and two-way ANOVA statistics followed by Bonferroni multiple comparisons test. $P<$ 0.05 was considered as statistically significant. For twoway ANOVA statistics computer program supplied by the site www.wessa.net [42] was used.

\section{Supplementary information}

Supplementary information accompanies this paper at https://doi.org/10. 1186/s12860-020-00275-0.

Additional file 1: Figure S1. Typical polarographic records showing the effect of diazoxide on the glutamate driven respiration of rat liver mitochondria. On the curves are shown the additions to standard incubation medium, the rates of respiration in ng-at. $0 \cdot \mathrm{min}^{-1} \cdot \mathrm{mg}^{-1}$, and the sequence of additions. Figure S2. The effect of diazoxide and valinomycin on the absorbance of mitochondrial suspension: A - typical time courses of mitochondrial swelling in standard incubation medium (control, 1) and after the addition of valinomycin (2) and diazoxide (3); B - absorbance changes under the same conditions. The data are mean of 3 independent experiments $\left(n=3 ; M \pm m ;{ }^{*}-P<0.05\right)$. Figure S3. A, B typical traces showing the time courses of BCECF fluorescence and absorbance in the absence (control) and the presence of $0.5 \mu \mathrm{M}$ of diazoxide. Other additions are shown on the legends; quinine was added at 0.5 $\mathrm{mM}, \mathrm{MgCl}_{2}$ at $1 \mathrm{mM}$. C, D - the typical changes in PBFI fluorescence in the absence $(1,2)$ and the presence of $D Z(3,4) i^{*}-P<0.05(3,4$ vs. 1,2$)$. Figure S4. A, B: Typical time courses of DCF fluorescence in rat liver mitochondria in standard incubation medium with the additions described in the legends. C: the changes in DCF fluorescence over 4 min of incubation. The data are means of 4 independent experiments $(n=4$; $\mathrm{M} \pm \mathrm{m}$; * $-\mathrm{P}<0.05$ as compared to controls without DZ).

\section{Abbreviations}

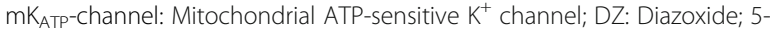
HD: 5-hydroxydecanoate; ROS: Reactive oxygen species; DCF: Dichlorofluorescein; BCECF: 2',7'-bis-(2-carboxyethyl)-5(6)carboxyfluorescein; PBFI: Potassium-binding benzofuran isophtalate; RCR: Respiratory control ratio

\section{Acknowledgments}

Not applicable.

\section{Authors' contributions}

OA designed research, analyzed and interpreted the results, wrote the paper; LK provided light absorbance and proton transport assays and related data analysis; VN conducted oxygen consumption studies and data analysis; IM and VS took part in discussion and interpretation of the results. All authors read and approved the final manuscript.

Funding

Not applicable. 


\section{Availability of data and materials}

The datasets used and/or analyzed during this study are available from the corresponding author on reasonable request.

\section{Ethics approval and consent to participate}

The work was conducted in accordance with "Guide for the Care and Use of Laboratory Animals" 8th ed. Washington, DC: National Research Council of the National Academies: The National Academic Press, 2011 approved by the Ethics Commission on Animal Experiments of A.A. Bogomoletz Institute of Physiology, NAS of Ukraine.

\section{Consent for publication}

Not applicable.

\section{Competing interests}

The authors declare that they have no competing interests.

\section{Author details}

${ }^{1}$ Circulation department, Bogomoletz Institute of Physiology, NAS of Ukraine, Bogomoletz str. 4, Kiev 01601, Ukraine. 'Hypoxic States Research Department, Bogomoletz Institute of Physiology, NAS of Ukraine, Kiev, Ukraine.

Received: 12 August 2019 Accepted: 7 April 2020

Published online: 19 April 2020

\section{References}

1. Garlid KD, Costa AD, Quinlan CL, Pierre SV, Dos Santos P. Cardioprotective signaling to mitochondria. J Mol Cell Cardiol. 2009;46:858-66.

2. Daiber A. Redox signaling (cross-talk) from and to mitochondria involves mitochondrial pores and reactive oxygen species. Biochim Biophys Acta. 1797;2010:897-06.

3. Zhang F, Cui J, Lv B, Yu B. Nicorandil protects mesenchymal stem cells against hypoxia and serum deprivation-induced apoptosis. Int J Mol Med. 2015;36(2):415-23.

4. Lucas AM, Caldas FR, da Silva AP, Ventura MM, Leite IM, Filgueiras AB, Silva CG, Kowaltowski AJ, Facundo HT. Diazoxide prevents reactive oxygen species and mitochondrial damage, leading to anti-hypertrophic effects. Chem Biol Interact. 2016;261:50-5.

5. Rozova EV, Mankovskaya IN, Belosludtseva NV, Khmil NV, Mironova GD. Uridine as a protector against hypoxia-induced lung injury. Sci Rep. 2019; 9(1):9418. https://doi.org/10.1038/s41598-019-45979-2.

6. Alberici LC, Oliveira HCF, Paim BA, Mantello CC, Augusto AC, Zecchin KG, Gurgueira SA, Kowaltowski AJ, Vercesi AE. Mitochondrial ATP-sensitive K ${ }^{+}$ channels as redox signals to liver mitochondria in response to hypertriglyceridemia. Free Radic Biol Med. 2009;47(10):1432-9.

7. Liang W, Chen M, Zheng D, Li J, Song M, Zhang W, Feng J, Lan J. The opening of ATP-sensitive $\mathrm{K}^{+}$channels protects $\mathrm{H} 9 \mathrm{c} 2$ cardiac cells against the high glucose-induced injury and inflammation by inhibiting the ROSTLR4-necroptosis pathway. Cell Physiol Biochem. 2017;41(3):1020-34.

8. Storey NM, Stratton RC, Rainbow RD, Standen NB, Lodwick D. Kir6.2 limits $\mathrm{Ca}(2+)$ overload and mitochondrial oscillations of ventricular myocytes in response to metabolic stress. Am J Physiol Heart Circ Physiol. 2013;305(10) H1508-18.

9. Mironova GD, Khrenov MO, Talanov EY, Glushkova OV, Parfenyuk SB, Novoselova TV, Lunin SM, Belosludtseva NV, Novoselova EG, Lemasters JJ. The role of mitochondrial KATP channel in anti-inflammatory effects of uridine in endotoxemic mice. Arch Biochem Biophys. 2018;654:70-6.

10. Coetzee WA. Multiplicity of effectors of the cardioprotective agent, diazoxide. Pharmacol Ther. 2013;140(2):167-75.

11. Laskowski M, Augustynek B, Kulawiak B, Koprowski P, Bednarczyk P, Jarmuszkiewicz W, Szewczyk A. What do we know about mitochondrial potassium channels? Biochim Biophys Acta. 1857;2016:1247-57.

12. Garlid KD, Paucek $P$, Yarov-Yarovoy $V$, Sun $X$, Schindler PA. The mitochondrial $K_{\text {ATP }}$ channel as a receptor for potassium channel openers. J Biol Chem. 1996;271:8796-9.

13. Garlid KD, Paucek P. Mitochondrial potassium transport: the $\mathrm{K}^{+}$-cycle. Biochim Biophys Acta. 1606:2003:23-41.

14. Jarmuszkiewicz W, Szewczyk A. Energy-dissipating hub in muscle mitochondria: potassium channels and uncoupling proteins. Arch Biochem Biophys. 2019;664:102-9. https://doi.org/10.1016/j.abb.2019.01.036.
15. Kowaltowski AJ, Seetharaman S, Paucek P, Garlid KD. Bioenergetic consequences of opening ATP-sensitive $\mathrm{K}^{+}$-channel of heart mitochondria. Am J Phys. 2001;280:H649-57.

16. Dröse $\mathrm{S}$, Brandt U, Hanley PJ. $\mathrm{K}^{+}$-independent actions of diazoxide question the role of inner membrane KATP channels in mitochondrial cytoprotective signaling. J Biol Chem. 2006;281:23733-9.

17. Jaburek M, Yarov-Yarovoy V, Paucek P, Garlid KD. State-dependent inhibition of the mitochondrial $K_{\text {ATP }}$ channel by glyburide and 5-hydroxydecanoate. J Biol Chem. 1998:273:13578-82.

18. Akopova OV, Nosar VI, Bouryi VA, Mankovska IN, Sagach VF. Influence of ATP-dependent $\mathrm{K}^{+}$-channel opener on $\mathrm{K}^{+}$-cycle and oxygen consumption in rat liver mitochondria. Biochem Mosc. 2010;75(10):1139-47.

19. Beavis AD. Upper and lower limits of the charge translocation stoichiometry of mitochondrial electron transport. J Biol Chem. 1987;262:6165-73.

20. Gelband CH, Ishikawa T, Post JM, Keef KD, Hume JR. Intracellular divalent cations block smooth muscle $K^{+}$channels. Circ Res. 1993;73:24-34.

21. Massari S, Azzone GF. The mechanism of ion translocation in mitochondria. Coupling of $\mathrm{K}^{+}$and $\mathrm{H}^{+}$fluxes. Eur J Biochem. 1970;12:301-9.

22. Andrukhiv A, Costa AD, West IC, Garlid KD. Opening mitoK Atp $_{\text {increases }}$ superoxide generation from complex I of the electron transport chain. Am J Phys. 2006;291:H2067-74.

23. Bajgar R, Seetharaman S, Kowaltowski AJ, Garlid KD, Paucek P. Identification and properties of a novel intracellular (mitochondrial) ATP-sensitive potassium channel in brain. J Biol Chem. 2001;276:33369-74.

24. Brierley GP, Jung DW. Kinetic properties of the $\mathrm{K}^{+} / \mathrm{H}^{+}$antiport of heart mitochondria. Biochemistry. 1990;29:408-15

25. Facundo HTF, Carreira RS, de Paula JG, Santos CCX, Ferranti R, Laurindo FRM, Kowaltowski AJ. Ischemic preconditioning requires increases in reactive oxygen release independent of mitochondrial $\mathrm{K}^{+}$channel activity. Free Radic Biol Med. 2006;40:469-79.

26. Akopova O, Nosar V, Gavenauskas B, Bratus L, Kolchinskaya L, Mankovska I, Sagach V. (2016) the effect of ATP-dependent potassium uptake on mitochondrial functions under acute hypoxia. J Bioenerg Biomembr. 2016; 48:67-5.

27. Riess ML, Camara AK, Heinen A, Eells JT, Henry MM, Stowe DF. KATP channel openers have opposite effects on mitochondrial respiration under different energetic conditions. J Cardiovasc Pharmacol. 2008;51:483-91.

28. Kopustinskiene DM, Liobikas J, Skemiene K, Malinauskas F, Toleikis A. Direct effects of $K_{\text {ATP }}$ channel openers pinacidil and diazoxide on oxidative phosphorylation of mitochondria in situ. Cell Physiol Biochem. 2010;25:181-6.

29. Pasdois $P$, Beauvoit $B$, Tariosse L, Vinassa B, Bonoron-Adele S, Dos Santos $P$. Effect of diazoxide on flavoprotein oxidation and reactive oxygen species generation during ischemia-reperfusion: a study on Langendorff perfused rat hearts using optic fibers. Am J Phys. 2008;294:H2088-97.

30. Adebiyi A, McNally EM, Jaggar $\mathrm{JH}$. Sulfonylurea receptor-dependent and -independent pathways mediate vasodilation induced by ATP-sensitive $\mathrm{K}^{+}$ channel openers. Mol Pharmacol. 2008;74(3):736-43.

31. Wojtovich AP, Urciuoli WR, Chatterjee S, Fisher AB, Nehrke K, Brookes PS. Kir6.2 is not the mitochondrial KATP channel but is required for cardioprotection by ischemic preconditioning. Am J Phys. 2013;304:H1439-45.

32. Henn MC, Janjua MB, Kanter EM, Makepeace CM, Schuessler RB, Nichols CG, Lawton JS. Adenosine triphosphate-sensitive potassium channel Kir subunits implicated in cardioprotection by diazoxide. J Am Heart Assoc. 2015:4: e002016. https://doi.org/10.1161/JAHA.115.002016.

33. Foster DB, Ho AS, Rucker J, Garlid AO, Chen L, Sidor A, Garlid KD, O'Rourke B. Mitochondrial ROMK channel is a molecular component of mitoK (ATP). Circ Res. 2012;111(4):446-54.

34. Laskowski M, Augustynek B, Bednarczyk P, Żochowska M, Kalisz J, O'Rourke B, Szewczyk A, Kulawiak B. Single-Channel Properties of the ROMK-PoreForming Subunit of the Mitochondrial ATP-Sensitive Potassium Channel. Int J Mol Sci. 2019;20(21):E5323. https://doi.org/10.3390/ijms20215323.

35. Paggio A, Checchetto V, Campo A, Menabò R, Di Marco G, Di Lisa F, Szabo I, Rizzuto R, De Stefani D. Identification of an ATP-sensitive potassium channel in mitochondria. Nature. 2019:572(7771):609-13. https://doi.org/10.1038/ s41586-019-1498-3.

36. Oldenburg O, Cohen MV, Yellon DM, Downey JM. Mitochondrial K (ATP) channels: role in cardioprotection. Cardiovasc Res. 2002;55(3):429-37.

37. Akopova OV, Kolchinskaya LI, Nosar VI, Bouryi VA, Mankovska IN, Sagach VF. Effect of potential-dependent potassium uptake on production of reactive oxygen species in rat brain mitochondria. Biochemistry (Mosc). 2014;79(1):44-53. 
38. Tahara EB, Navarete FD, Kowaltowski AJ. Tissue-, substrate-, and site-specific characteristics of mitochondrial reactive oxygen species generation. Free Radic Biol Med. 2009;46(9):1283-97.

39. Liu S-S. Cooperation of a "reactive oxygen cycle" with the Q cycle and the proton cycle in the respiratory chain - superoxide generating and cycling mechanisms in mitochondria. J Bioenerg Biomembr. 1999;31:367-76.

40. Salgado-Puga K, Rodríguez-Colorado J, Prado-Alcalá RA, Peña-Ortega F. Subclinical doses of ATP-sensitive potassium channel modulators prevent alterations in memory and synaptic plasticity induced by amyloid- $\beta$. J Alzheimers Dis. 2017;57:205-26.

41. Karlsson M, Kurz T, Brunk UT, Nilsson SE. Frennesson Cl (2010) what does the commonly used DCF test for oxidative stress really show? Biochem J. 2010;428(2):183-90.

42. Wessa P. Free statistics software, Office for research development and education, version 1.2.1. 2020; URL https://www.wessa.net/.

\section{Publisher's Note}

Springer Nature remains neutral with regard to jurisdictional claims in published maps and institutional affiliations.

Ready to submit your research? Choose BMC and benefit from:

- fast, convenient online submission

- thorough peer review by experienced researchers in your field

- rapid publication on acceptance

- support for research data, including large and complex data types

- gold Open Access which fosters wider collaboration and increased citations

- maximum visibility for your research: over $100 \mathrm{M}$ website views per year

At BMC, research is always in progress.

Learn more biomedcentral.com/submissions 